https://doi.org/10.47370/2078-1024-2021-13-3-104-114

УДК 37.011.

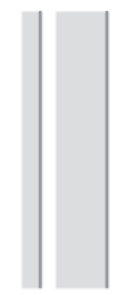

Лебедева И.В., Лощилова А.А.

МОДЕЛЬ ПРОФЕССИОНАЛЬНОГО ПРОФИЛЯ КЛАССНОГО РУКОВОДИТЕЛЯ: ФОРМАТЫ ДЕЯТЕЛЬНОСТИ

\begin{abstract}
Лебедева Ирина Владимировна, кандидат педагогических наук, доиент, дочент кафедры общей и сочиильной педагогики ФГБОУ ВО «Нижегородский государственный педагогический университет имени Козьмы Минина, Нижний Новгород, Россия, e-mail: lebedeva06.08@yandex.ru, тел.: +7 (910) 8786238

Лощилова Анна Александровна, кандидат педагогических наук, дочент кафедры общей и сочиальной педагогики ФГБОУ ВО «Нижегородский государствениый педагогический университет имени Козьмы Минина, Нижний Новгород, Россия, e-mail: annet 787@,mail.ru тел.: +7 (920) 2991496
\end{abstract}

\title{
БЛАГОДАРНОСТИ
}

Федеральное государственное бюджетное образовательное учреждение высшего образования «Нижегородский государственный педагогический университет имени Козьмы Минина» реализует проект НИР «Оценка эффективности деятельности классного руководителя (в т.ч. разработка критериев эффективности)» (730000Ф.99.1.БВ10АА00006) за счет средств федерального бюджета в рамках выполнения государственного задания

$$
\text { № 073-00081-21-02 от 14.07.2021 г. }
$$

\section{NOTE OF ACKNOWLEDGMENT}

The Federal State Budgetary Educational Institution of Higher Education "Nizhny Novgorod State Pedagogical University named after Kozma Minin" is implementing the research project "Assessment of the effectiveness of a class teacher (including the development of performance criteria)" (730000F.99.1BV10AA00006) at the expense of the federal budget within the framework fulfillment of state assignment No. 073-00081-21-02 of July 14, 2021

\section{Аннотация}

Программные документы, формирующие государственную образовательную политику в стране, исследования современных образовательных моделей и практик доказывают приоритетность решения проблемы воспитания подрастающего поколения. Возрастает статус и повышается роль классного руководителя в образовательном пространстве школы, что 
определяет необходимость разработки качественных инструментов его профессиональноличностного развития.

Проблема исследования: определение и систематика современных форматов деятельности классного руководителя в образовательной организации.

Цель исследования: проектирование модели профессионального профиля классного руководителя в соответствии с форматами его профессиональной деятельности и саморазвития.

Методы исследования: критический анализ педагогических, психологических и нормативно-правовых источников, сопоставительный анализ феноменов воспитательных практик на основе парадигмального подхода, проектирование, моделирование, систематизация

Результаты исследования: проанализирована педагогическая деятельность в разных исторических контекстах; определены стратегические векторы профессиональной работы классного руководителя как организатора и реализатора воспитательных событий; обоснована необходимость создания многоаспектного профессионального профиля классного руководителя; разработана его интегративная модель, отражающая все форматы профессиональной деятельности и личностного развития.

Ключевые выводы: разработанная модель профессионального профиля классного руководителя является основой определения его фундаментальных характеристик как воспитателяпрофессионала и саморазвивающейся личности. Представленный профиль позволяет анализировать практическую работу классного руководителя по различным параметрам и является инструментом для построения механизма оценивания его профессионального труда.

Ключевые слова: воспитание, модель профессионального профиля классного руководителя, профессиональный профиль классного руководителя, классный руководитель, воспитательная практика, событийность, детско-взрослое сообщество.

Для циттирования: Лебедева И.В., Лощилова А.А. Модель профессионального профиля классного руководителя: форматы деятельности // Вестник Майкопского государственного технологического университета. 2021. Том 13, № 3. С. 104-114. https:// doi.org/10.47370/2078-1024-2021-13-3-104-114.

Lebedeva I. V., Loshchilova A. A.

\section{MODEL OFTHE PROFESSIONAL PROFILE OF A CLASS TEACHER: FORMATS OF ACTIVITY}

Lebedeva Irina Vladimirovna, Candidate of Pedagogy, an associate professor, an assistant professor of the Department of General andiSocial Pedagogics of Nizhny Novgorod State Pedagogical University named after Kozma Minin, Nizhny Novgorod, Russia,

e-mail: lebedeva06.08@yandex.ru

tel.: $+7 .(910) 8786238$

Loshchilova Anna Aleksandrovna, Candidate of Pedagogy, an associate professor, an assistant professor of the Department of General and Social Pedagogics of Nizhny Novgorod State Pedagogical University named after Kozma Minin, Nizhny Novgorod, Russia,

e-mail: annet_787@mail.ru

tel.: +7.(920) 2991496 


\section{Annotation}

Program documents that form the state educational policy in the country, studies of modern educational models and practices prove the priority of solving the problem of educating the younger generation. In this regard, the status and role of the class teacher in the educational space of the school increases, which determines the need to develop high-quality tools for his professional and personal development. The problem of the study: the definition and systematics of modern formats of the class teacher's activity in an educational organization. The purpose of the study: designing a model of the professional profile of the class teacher in accordance with the formats of his professional activity and self-development. Research methods: critical analysis of pedagogical, psychological and regulatory sources, comparative analysis of the phenomena of educational practices based on a paradigmatic approach, design, modeling, vectors of the class teacher's professional work as an organizer and implementer of educational events; the need for a multidimensional professional profile of the class teacher is justified; its integrative model is developed, reflecting all formats of professional activity and personal development. Key conclusions: the developed model of the professional profile of the class teacher is the basis for determining his fundamental characteristics as a professional educator and a self-developing personality. The presented profile allows you to analyze the practical work of the class teacher according to various parameters and is a tool for building a mechanism for evaluating his professional work.

Keywords: education, the model of the professional profile of a class teacher, the professional profile of a class teacher, a class teacher, educational practice, eventfulness, children's and adult community

For citation: Lebedeva I.V., Loshchilova A.A. Model of the professional profile of a class teacher: formats of activity // Vestnik Majkopskogo gosudarstvennogo tehnologiceskogo universiteta. 2021. Volume 13, No. 3. P. 104-114. https:/doi. org/10.47370/2078-1024-2021-13-3-104-114.

Актуальность проблемы. Воспитание сегодня определяется как стратегический общенациональный приоритет, в котором заключен мощный потенциал воздействия на процессы общественного развития, социализации, становления личности, включения детей и молодежи в сложную систему общественных отношений. Известная фраза академика Д.С. Лихачева о соотношении воспитания и образования («Образование, подчиненное задачам воспитания, - вот что нам нужно в XXI веке».) имеет сегодня особую актуальность и обретает качественное воплощение [9]. Не стоит доказывать, что эта идея верна в любую эпоху, т.к. «здоровое» общество состоит из добропорядочных, нравственно воспитанных граждан. Подтверждением данного тезиса могут служить исследования, посвященные диалектике историко-педагогического процесса, в которой высвечивается органичная связь между миссией воспитателя, его социальным статусом и перспективами развития отдельной личности и общества в целом (М.В. Богуславский, Г.Б. Корнетов, Е.Ю. Илалтдинова, Е.А. Слепенкова, И.В. Лебедева, С.И. Аксенов и др.). В силу этого рассмотрение современных вызовов общества, адресованных организаторам и реализаторам воспитательного процесса - классным наставникам, является обоснованным. Практика показывает, что и сегодня классных руководитель зачастую испытывает затруднения в построении продуктивных отношений со своими учениками. Остается актуальной проблема поиска классными руководителями современных форм, методов и моделей воспитательной деятельности. Учесть и выстроить качественную стратегию воспитания и профессионально ответить на социальные потребности и ожидания современного общества может педагог с уверенной позицией Воспитателя. 
Всё вышесказанное позволяет определить цель исследования: проектирование профессионального профиля классного руководителя общеобразовательной организации в соответствии с новыми форматами его воспитательной деятельности и личностного роста.

Теоретическое обоснование. Составляя портрет современного классного наставника, стоит отметить, что на протяжении многих столетий понятия воспитатель, учитель и педагог были практически синонимами, соответственно, педагогическая деятельность «по умолчанию» включала в себя и обучающую, и воспитывающую функции, сопряженные с развивающей и просветительской. В рамках парадигмального подхода к анализу явлений и феноменов действительности доказано, что в любую историческую эпоху происходит поиск «идеального» учителя (педагога, наставника), который сумел бы воспитать нравственное поколение граждан общества $[1 ; 3 ; 6 ; 14]$. Теоретический анализ данного вопроса важен для составления портрета наставника современной школы, который может качественно строить воспитательные отношения как с отдельным учеником, так и с сообществом детей, их родителей и иными субъектами образовательного процесса. На наш взгляд, оценить качества «идеального» педагога-воспитателя целесообразно с разных позиций: через его личностные качества; уникальность самой педагогической деятельности (профессии); соответствие общественным ожиданиям; через запросы человека (обучающегося). В данном контексте можно с уверенностью утверждать, что интеграция всех этих подходов и определяет сегодня общечеловеческую «сквозную» миссию педагога - воспитать нравственную личность [6]. Стоит отметить, что ключевое понятие воспитания определяет генеральный вектор педагогической деятельности, что подтверждает многовековой опыт образовательных (соответственно, и воспитательных) практик, экспериментальной работы, построения теоретических моделей. Его анализ позволил сформулировать следующие константы: 1) воспитание - средство становления человека; 2) воспитание всегда природо- и культуросообразно; 3) воспитание осуществляется под влиянием множества факторов; 4) воспитание - мощный фактор общественно-экономического развития общества.

Тем не менее, многие вопросы, связанные с фундаментальным для педагогики и образования понятием воспитания, остаются проблемными и сегодня. Такое происходит при анализе сложных, многозначных, полифункциональных явлений или феноменов [14]. Известно, что в педагогической науке трактовок термина «воспитание) немало и каждая имеет право на существование. Например, морфологически термин «воспитание» связан со словами «питать», «напитывать», «питание». Из этого следует понимание воспитания как «напитывание» (или («наполнение») растущего человека духовными ценностями и нравственными смыслами. Такое толкование при всей его простоте наверняка можно использовать для определения воспитания в его общем широком значении.

Современное научное определение термину «воспитание» дает Федеральный закон «Об образовании в Российской Федерации»: «воспитание - деятельность, направленная на развитие личности, создание условий для самоопределения и социализации обучающегося на основе социокультурных, духовнонравственных ценностей и принятых в обществе правил и норм поведения в интересах человека, семьи, общества и государства) (Федеральный закон от 29.12.2012 № 273-Ф3 (ред. от 02.07.2021) «Об образовании в Российской Федерации»). Системообразующими терминами данного определения вполне можно считать деятельность, условия, ценности, 
и их взаимосвязь позволяет истолковать воспитание как деятельность педагога, направленная на создание условий для интериоризации учениками ценностей своего времени, а именно путь «восхождения) человека к ценностям общества делает его личностью.

Тем не менее, разночтения и дискуссии на тему воспитания как такового и организации воспитательной практики, в частности, ведутся на разных уровнях: теоретическом, методологическом, технологическом $[1 ; 2 ; 8]$. Не вызывает сомнений утверждение, что воспитательная работа в школе связана, прежде всего, с классным руководством, и именно на классного руководителя общество во3лагает ответственность за формирование личности ученика - будущего гражданина страны. Стоит отметить, что классный руководитель всегда воспринимался как специалист в области построения эффективных воспитательных отношений. Так, в 2020 году Президент России Владимир Путин в рамках своего ежегодного послания Федеральному Собранию особо выделил вопросы воспитания школьников и классного руководства: «Ближе всего к ученикам - их классный руководитель. Такая постоянная каждодневная работа, связанная с обучением, воспитанием детей, - это огромная ответственность, и она требует особой подготовки наставников и их особой поддержки). Владимир Путин отметил, что классный руководитель - это воспитатель, и его деятельность являет собой «федеральную функцию» [10]. Эти слова четко и емко определили вектор развития института классного руководства в современной школе. Профессиональный стандарт педагога определил статус учителя как ключевой фигуры в образовании, а в качестве главных компетенций выделил «готовность к переменам, мобильность, способность к нестандартным трудовым действиям, ответственность и самостоятельность в принятии решений)) (профессиональный стандарт «Педагог (педагогическая деятельность в сфере дошкольного, начального общего, основного общего, среднего общего образования) (воспитатель, учитель)» утвержден Приказом Минтруда России от 18 октября 2013 г. № 544н [Электронный ресурс].

Примерная программа воспитания (2020) показывает, каким образом педагоги (учитель, классный руководитель, заместитель директора по воспитательной работе, старший вожатый, воспитатель, куратор, наставник, тьютор и т.п.) могут реализовать воспитательный потенциал их совместной с детьми деятельности и тем самым сделать свою школу воспитывающей организацией. В центре программы воспитания в соответствии с ФГОС общего образования находится личность обучающегося, ее становление и развитие.

Для того чтобы проанализировать современные реалии школьной жизни и, главное, определить происходящие перемены в практике воспитания, целесообразно обратиться к истории образования. Педагоги-исследователи единодушны в том, что образ современного икольника разительно отличается от того «ученика», на которого ориентировалась педагогика прошлых десятилетий. При этом ребенок не стал хуже или лучше, он просто стал другим. Он взрослеет в условиях:

- социального расслоения населения (в том числе детей и молодежи) по уровням обеспеченности и уровням образованности;

- интенсивно работающих с сознанием различных средств массовой информации и средств «компьютерной индустрии»;

- экспансии молодежной субкультуры, ориентирующей молодых людей на потребление;

- нарастания межнациональных, межконфессиональных, межпоколенных и иного рода межгрупповых напряжений и Т.д. [1]. 
Сегодня школьная жизнь - не привычная для ученика повседневность, а воспитательное пространство для реализации его предпочтений и самоопределения, где он сможет обрести жизненно важные компетенции, научиться строить позитивное общение, мыслить и творить. Пришло время наполнить новым содержанием главную идею Антона Макаренко о единстве воспитания и жизни. Она органично отражается в национальном проекте «Образование», где ключевой задачей заявлено создание условий, в которых детям будет комфортно развиваться, обретая общечеловеческие и ценности сообщества. Их целый комплекс, и они составляют аксиологический фундамент человеческой личности. Прежде всего, это ценности всечеловеческие (гуманистические), которые связаны с системой одобряемых и порицаемых поступков человека в жизни, о добре и зле, о нравственном и порочном. Понятно, что воспитание как социально обусловленный процесс отражает ценности социума. Речь идет об исторической памяти народа, уважении к своей стране, ее законам, нормам жизни, взаимоотношению поколений, к национальным, историческим, половозрастным, личностным ценностям, которые живут в каждом народе и в каждом человеке. В этом контексте целесообразно вспомнить педагогическую позицию К.Д. Ушинского о воспитании человека, согласно которой прежде чем его воспитывать, необходимо его познать и, в первую очередь, те внутренние смыслы, которые движут его личностным развитием [15].

Доказано, что сегодня меняется драматургия участников воспитательных отношений: классный руководитель воплощает союз двух перспектив: перспективы ученика и перспективы педагога. Перспектива ученика предполагает субъектную включенность, присвоение позитивных жизненных ориентиров, высокую степень приближения к нравственным и мировоззренческим ценностям, активное вовлечение в построение собственного образовательного маршрута. Перспектива педагога - в умении создавать гуманистическое воспитательное пространство, в котором обеспечиваются процессы самоопределения, самоутверждения и самореализации учащихся. Для того чтобы союз двух перспектив был успешен, надо знать современные подходы к организации воспитательного пространства $[2 ; 11 ; 12]$.

Менторинг и коучинг, тьюторство и наставничество, эффективная коммуникация, авторские программы воспитания детей, медиация, охранительная педагогика, адаптивные технологии, определение и сопровождение индивидуального образовательного маршрута обучающегося считаются перспективными точками роста современных воспитательных систем. Многие педагоги проявляют профессиональный интерес к проектированию индивидуальных воспитательных маршрутов как к средству реализации ФГОС ООО. Индивидуальный воститательный марирут (ИВМ) моделирует личное развитие каждого ребенка в классе, он разрабатывается с целью педагогически разумной дифференциации процесса воспитания и его своевременной, оперативной, ситуативно-тактической коррекции. Вместе с тем, любой воспитательный проект может быть признан воспитательным маршрутом всего класса при условии активного участия в нем всех обучающихся. Воспитательный марирут класса (ВМК) моделирует ожидаемое развитие всего классного коллектива. Он напрямую связан с концепцией самовоспитания и саморазвития личности обучающегося и предnолагает: а) преобразование процесса школьного воспитания в самовоспитание обучающегося; б) создание воспитательной среды, стимулирующей у личности потребности в самосовершенствовании; в) формирование социальной активности; 
г) формирование интегративного по своей природе качества самостоятельности личности - подготовки ребенка к социальной автономизации; д) обучение поведению в коллективе: общению, ответственности, дисциплинированности, самоуправлению и саморегуляции; е) подготовку учащихся к профессиональному и жизненному самоопределению, к профориентации и др.

С современными трендами в образовании успешно коррелируют ретроинновации, которые объединяют историю и современность. В воспитание вернулись ДОСААФ, зеленый патруль, школьная форма, РДШ, раздельное обучение, частные школы, комплекс ГТО, женские пансионы, казачья педагогика, скаутизм, негосударственное и религиозное образование.

Безусловно, важным является серьезное обращение к форматам детсковзрослых сообществ, в основе которых лежит идея единого коллектива, которую «подарил» мировой педагогике А.С. Макаренко и развивали В.А. Караковский, И.П. Иванов, ОС. Газман, А Н. Тубельский и продолжает реализовывать Е.А. Ямбург. Ненавязчивое, но продуктивное разнопоколенное взаимодействие, основанное на ненасильственном воспитании и совместном с ребенком исследовании и преобразовании мира - один из ведущих принципов современной гуманной педагогики. Грамотно построенный союз детей и взрослых образует естественную открытую событийную общность, которая проявляется не в формально запланированных мероприятиях, а в совместном проживании важных для всех событий. Значимым направлением воспитательной работы является развитие школьного самоуправления как атрибута духовной и гражданской взрослости учеников, как кредит доверия взрослых своим воспитанникам в различных событиях и ситуациях школьной жизни [16].

В федеральных государственных образовательных стандартах общего образования прописана современная модель воспитательной деятельности классного наставника, которая предполагает приоритетность внеурочной активности школьников. Деятельностный подход в образовании реализуется в системном построении воспитательной практики, наполненной детской активностью и творчеством. Известно, что зачастую педагоги придают работе с классом аспектный характер, когда воспитание укладывается в привычные направления (духовно-нравственное, эстетическое, гражданско-правовое и т.д.). Такой подход активно критикуется еще с 1930-х годов прошлого века. Но существует сила традиции, и единственной возможностью преодоления формализма и разрозненности воспитательных дел является перестройка педагогического мышления учительства на основе освоения событийного подхода. В отличие от аспектного подхода, событийный подход - не набор случайно отобранных и не связанных друг другом мероприятий, а системообразующие интегрированные формы деятельности (ключевые дела, творческие программы, дискуссионные площадки, волонтерство, социальные проекты, клубная работа и т.д.).

Специфической проблемой воспитания считается определение результативности воспитательных усилий. В широком смысле воспитательным результатом можно считать непосредственные духовно-нравственные «приращения» (приобретения) ребенка в процессе активного освоения воспитательного пространства. Так, Е.Н. Степанов выделяет характерные черты, из которых может складываться образ (модель) эффективной деятельности классного руководителя. К таким чертам автор относит следующие: 1) стратегическую устремленность и долгосрочную перспективу планирования процесса воспитания; 2) направленность содержания воспитательной деятельности на развитие детей; 3) системность 
осуществления воспитательного взаимодействия; 4) ориентацию воспитательного процесса на развитие индивидуальности детей; 5) технологичность работы педагога-воспитателя; 6) диагностическую оснащенность деятельности классного руководителя [11, с. 211].

Для осмысления современных исследований в области профессионального уровня педагогов-воспитателей сегодня используется относительно новый для образовательного контекста термин «профессиональный профиль классного руководителя». Определено, что профессиональный профиль обладает идеально-интенциальной природой, выступая эталоном, стратегическим образом результата профессиональной деятельности $[7 ; 13]$. Профессиональный профиль классного руководителя понимается нами как система общих требований к профессиональной деятельности, совокупности компетенций и личностных качеств, необходимых классному руководителю для эффективного и качественного выполнения должностных обязанностей. Следовательно, профессиональный профиль является не только эффективным инструментом комплексной оценки профессиональных качеств и компетенций классного руководителя, но и способствует повышению его мотивации к профессиональному росту и дальнейшему развитию. Не менее значим данный профиль и в процессе профессионального воспитания будущих педагогов. Основанное на принципах свободы, осознанности, конвенции поколений, совместном «проживании» детьми и взрослыми образовательной действительности профессиональное воспитание ориентировано на формирование профессионального мировоззрения на основе развития базового духовно-нравственного императива личности (С.В. Фролова) [16, с. 4].

Вместе с тем, несмотря на важность и значимость оценки деятельности классного руководителя, в теории образования отсутствует четкое представление о структуре и содержании профессионального профиля классного руководителя, что актуализирует необходимость построения его модели. Разработанная нами модель профессионального профиля классного руководителя предполагает многоаспектное рассмотрение профессионально-личностных характеристик в структуре его деятельности и профессионального роста. Представим данную модель детально.

Модель профессионального профиля классного руководителя

Теоретической основой модели профессионального профиля классного руководителя явились положения профессиографии; методологическим фундаментом выступили компетентностный, личностный и деятельностный подходы, а также принципы научности, комплексности, реального отражения состояния профессии в конкретных социально-экономических условиях, учета перспектив профессионального роста специалиста.

Содержательное «наполнение» структурных компонентов модели профессионального профиля классного руководителя определено целевыми приоритетами и требованиями, отраженными в документах, регламентирующих деятельность классного руководителя (Федеральный закон от 29.12.2012 № 273-Ф3 (ред. от 02.07.2021) «Об образовании в Российской Федерации», Указ Президента Российской Федерации от 7 мая 2018 г. № 204 «О национальных целях и стратегических задачах развития Российской Федерации на период до 2024 года), Стратегия развития воспитания в Российской Федерации на период до 2025 года, Примерная программа воспитания) [5].

Структура модели профессионального профиля классного руководителя включает следующие ключевые компоненты:

I. Ориентировочно-целевой компонент представлен целью и задачами 
деятельности классного руководителя, определяемыми базовыми целями и принципами воспитания и социализации личности.

II. Функционально-организационный компонент содержит общие требования к профессиональной деятельности классного руководителя, отражающие: 1) место классного руководителя в структуре управления школой, 2) характеристику профессиональных функций, 3) сферу ответственности и полномочий, 4) особенности профессиональных коммуникаций, 5) перечень регламентирующей документации, предусмотренной для должности, 6) требования к условиям труда и организации рабочего места.

Отметим, что характеристика профессиональных функций классного руководителя структурирована по ключевым направлениям осуществляемой им воспитательной работы: 1) индивидуально с личностью обучающегося; 2) с классом; 3) в союзе с родителями; 4) во взаимодействии с педагогическим коллективом [11].

III. Содержательный компонент включает описание совокупности приоритетных личностных качеств и компетенций (психолого-педагогической, информационно-коммуникационной, тьюторской, управленческой, проектной, коммуникативной, связанной c soft-компетенциями), позволяющих классному руководителя эффективно и качественно выполнять свои профессиональные обязанности.

Они декомпозированы по компонентам. Абрис степени их сформированности отражает следующие уровни для компетенций: базовый, повышенный, уровень мастерства; для личностных качеств: низкий, высокий, средний.

IV. Результативно-оценочный компонент раскрывает диагностический инструментарий: критерии, количественные и качественные показатели, диагностические методики оценки эффективности профессиональной деятельности классного руководителя. Не менее значимо «насыщение» данного блока индикаторами и методиками оценки степени освоения классным руководителем профессиональных компетенций и качеств.

Заключение. Включенность классного руководителя в решение многообразных проблем и различных педагогических ситуаций, возникающих в процессе работы с отдельной личностью, классом, родителями учащихся, социальными партнерами, коллегами и т.п., требуют от него высокого уровня профессионализма. Профессиональный профиль классного руководителя, который интегрирует ориентировочно-целевой, функционально-организационный, содержательный и результативно-оценочный компоненты, является интегративной «матрицей» труда классного наставника нового формата. Спецификой профессионального профиля классного руководителя является приоритет его воспитательной деятельности, направленной на создание детско-взрослого сообщества и организацию продуктивной событийной активности всех участников образовательного пространства. Представленная модель профессионального профиля классного руководителя позволяет управлять процессами его мотивации и адаптации на рабочем месте, функционирования в профессиональной деятельности, провести качественную оценку труда. Кроме того, она является важным инструментом в определении качества воспитательных возможностей классного наставника и позволяет выстроить траектории его развития как личности и профессионала.

\section{ЛИТЕРАТУРА:}

1. Фролов А.А., Илалтдинова Е.Ю., Аксёнов С.И. Воспитание как социальное явление и как педагогическая деятельность: преодоление разрыва (по наследию А.С. Макаренко) // Психолого-педагогический поиск. 2018. № 1 (45). С. 38-43. 
2. Власенко В.В. Культурологический смысл фразы «учитель - ключевая фигура...» // Исторические, философские, политические и юридические науки, культурология и искусствоведение. Вопросы теории и практики. 2014. № 10 (48). С. 54-58.

3. Ilaltdinova E.Y., Frolova S.V., Lebedeva I.V. Top Qualities of Great Teachers: National and Universal // Advances in Intelligent Systems and Computing. 2018. Vol. 677. P. 44-52.

4. In the Search of National Ideal of Russian Pedagogue /. S.I. Aksenov [et al.] //. Journal of Entrepreneurship Education. 2017. Vol. 20, No. 3.

5. Информационный бюллетень №3. Классное руководство в государственных образовательных организациях субъектов РФ и муниципальных образовательных организациях, реализующих образовательные программы начального общего, основного общего и среднего общего образования, в т.ч. адаптированные основные общеобразовательные программы [Электронный ресурс] // Сборник нормативных правовых актов, рекомендаций и разъяснений /. сост. В.Н. Понкратов. М., 2020. Режим доступа: mgoprof.ru

6. Лебедева И.В., Фомина Н.В., Ревина И.А. Исторический контекст осмысления миссии педагога //. Проблемы современного педагогического образования. 2018. № 59-1. C. 208-211.

7. Лебедева И.В., Радостина Н.Б. Профессиональное наставничество в образовательной организации: традиции и инновации /. Проблемы современного педагогического образования. 2017. № 55-10. С. 149-156.

8. Лебедева И.В., Аксенов С.И. Учитель или коуч? // Современные проблемы науки и образования. 2014. № 6. С. 807.

9. Лихачев Д.С. О национальном характере русском // Вопросы философии. 1990. № 4.

10. Послание Президента РФ Федеральному Собранию от 15.01.2020 «Послание Президента Федеральному Собранию» [Электронный ресурc]. URL: http://www.consultant.ru/document/. cons_doc_LAW_342959/).

11. Степанов Е.Н. Воспитательная деятельность классного руководителя: современная модель //. Вестник КГУ им. Н.А. Некрасова. 2009. Т. 15. С. 211-215.

12. Степанова И.В., Парфенова И.С. Модуль «Классный руководитель» в школьной программе воспитания // Отечественная и зарубежная педагогика. 2020. Т. 2, № 1 (67). С. 62-70.

13. Стрыгина В.В. Профиль должности как системообразующий метод стандартизации должностей предприятия // Социальная психология и общество. 2013. № 1. С. 131-136.

14. Phenomenon of a Teacher Within a Historical Context/. Ilaltdinova E. [et al.] // SHS Web of Conferences 50, 01016 (2018) https://doi.org/10.1051/shsconf/20185001016 CLLDIAH-2018

15. Ушинский К.Д. Человек как предмет воспитания. Опыт педагогической антропологии. М.: ФАИР-ПРЕСС, 2004. 576 с.

16. Фролова С.В. Профессиональное воспитание будущего учителя: дискуссия о концептуальных положениях //. Вестник Мининского университета. 2021. Т. 9, № 2. С. 4.

\section{REFERENCES:}

1. Frolov A.A., Ilaltdinova E.Y., Aksenov S.I. Education as a Social Phenomenon and as a Pedagogical Activity: Overcoming the Gap (according to the legacy of A.S. Makarenko) // Psychological and pedagogical search. 2018. № 1 (45). P. 38-43.

2. Vlasenko V.V. The cultural meaning of the phrase "The teacher is a key figure..." //. Historical, philosophical, political and legal sciences, cultural studies and art criticism. Questions of theory and practice Tambov: Diploma. 2014. No. 10 (48). P. 54-58.

3. Ilaltdinova E.Y., Frolova S.V., Lebedeva I.V. Top Qualities of Great Teachers: National and Universal // Advances in Intelligent Systems and Computing. 2018. Vol. 677. P. 44-52. 
4. In the Search of National Ideal of Russian Pedagogue / S.I. Aksenov [et al.] // Journal of Entrepreneurship Education. 2017. Vol. 20. No 3.

5. Information Bulletin No. 3. Classroom management in state educational organizations of the subjects of the Russian Federation and municipal educational organizations that implement educational programs of primary general, basic general and secondary general education, including adapted basic general education programs. Collection of normative legal acts, recommendations and explanations [Electronic resource] /.V.N. Ponkratov. M., 2020. Access mode: mgoprof.ru

6. Lebedeva I.V., Fomina N.V., Revina I.A. The historical context of understanding the teacher's mission //. Problems of modern pedagogical education. 2018. No. 59-1. P. 208-211.

7. Lebedeva I.V., Radostina N.B. Professional mentoring in an educational organization: traditions and innovations //. Problems of modern pedagogical education. 2017. No. 55-10. P. 149-156.

8. Lebedeva I.V., Aksenov S I. A teacher or a coach? //. Modern problems of science and education. 2014. No. 6. P. 807.

9. Likhachev D.S. On the national character of Russian // Problems of Philosophy. 1990. No. 4.

10. Message of the President of the Russian Federation to the Federal Assembly of 15.01.2020 "Message of the President to the Federal Assembly" URL: http://www.consultant.ru//document/. cons_doc_LAW_342959/).

11. Stepanov E.N. Educational activity of the class teacher: a modern model // Bulletin of the KSU named after N. A. Nekrasov. 2009. Vol. 15. P. 211-215.

12. Stepanova I.V., Parfenova I.S. Module "Class teacher" in the school education program // Domestic and foreign pedagogy. 2020. Vol. 2, No. 1 (67). P. 62-70.

13. Strygina V.V. Position profile as a system-forming method of standardization of enterprise positions // Social psychology and society. 2013. No. 1. P. 131-136.

14. Phenomenon of a Teacher Within a Historical Context /. Ilaltdinova E. [et al.] //. SHS Web of Conferences 50, 01016 (2018) https://doi.org/10.1051/shsconf/20185001016 CILDIAH-2018

15. Ushinsky K.D. Man as a subject of education. Experience in pedagogical anthropology. M.: FAIR-PRESS, 2004. $576 \mathrm{p}$.

16. Frolova S.V. Professional education of a future teacher: a discussion about conceptual provisions // Bulletin of the Mininsky University. 2021. Vol. 9, No. 2. P. 4. 